\title{
CÁDMIO EM LATOSSOLO VERMELHO CULTIVADO COM MILHO EM COLUNAS: MOBILIDADE E BIODISPONIBILIDADE ${ }^{(1)}$
}

\author{
M. A. J ULIATTI(2), R. M. PRADO(3), \\ M. F. BARRIQUELO(2) \& E. LENZI (4)
}

\begin{abstract}
RESUMO
Com vistas em avaliar a di nâmi ca do cádmio no sistema solo-planta, instalouse um experimento em colunas de PVC (0,10 m de diâmetro e $0,80 \mathrm{~m}$ de altura), preenchidas com amostras de Latossolo Vermel ho distrófico típico com $320 \mathrm{~g} \mathrm{~kg}^{1}$ de argila (elevou-se V \% a 70) onde se aplicou biossólido (pH 6) contaminado com Cd, incorporado na camada de 0-0,2 m da coluna. Os tratamentos com biossólido contami nado com cádmio foram ( $\mathrm{mg} \mathrm{kg}^{-1}$ ): 0 (testemunha), 2.500 e 5.000 de $\mathrm{Cd}$ e dois adicionais ( $2.500 \mathrm{Cd}+2.500 \mathrm{~Pb}$ e $5.000 \mathrm{Cd}+5.000 \mathrm{~Pb}$ ). Cultivou-se milho nas colunas por um período de 80 dias. As concentrações de $\mathrm{Cd}$ nas amostras de solo e na parte aérea do mi l ho foram determi nadas em extrato nitroperclórico. A alta concentração do $\mathrm{Cd}$ no solo restringiu-se apenas à camada de incorporação, não havendo lixiviação do elemento na coluna do solo. A concentração de $12 \mathrm{mg} \mathrm{kg}^{-1}$ de $\mathrm{Cd}$ não foi suficiente para provocar sintomas visuais de fitotoxidez de $\mathbf{C d}$ em mi lho. $\mathrm{O} \mathbf{P b}$ adicionado juntamente com o $\mathbf{C d}$ não apresentou interferência no sistema solo-planta.
\end{abstract}

Termos de indexação: lodo de esgoto, lixiviação, toxidez, $\mathbf{P b}$.

(1) Parte da Tese de Mestrado do primeiro autor, apresentada à Universidade Estadual de Maringá - UEM. Recebido para publicação em agosto de 2001 e aprovado em junho de 2002.

(2) Mestre, Departamento de Química da Universidade Estadual de Maringá - UEM. Av. Colombo 5790, CEP 87020-900 Maringá (PR). E-mail: mari-juliatti@yahoo.com.br

(3) Doutorando, Departamento de Solos e Adubos da Faculdade de Ciências Agrárias e Veterinárias - UNESP. Via de Acesso Prof. Paulo Donato Castellane, s/nº, CEP 14870-000 J aboticabal (SP). Bolsista FAPESP. E-mail: rmprado@fcav.unesp.br

(4) Professor do Departamento de Química, UEM. E-mail: elenzi@maringa.com.br 


\title{
SUMMARY: CADMIUM IN TYPIC HAPLUDOX COLUMNS CULTIVATED WITH MAIZE: MOBILITY AND BIOAVAILABILITY
}

\begin{abstract}
Cadmium dynamics in the soil-plant system were evaluated in an experiment with a Typic Hapludox (320 g kg-1 of day) PVC columns (diameter $0.10 \mathrm{~m}$, height $0.80 \mathrm{~m}$ ) were filled with soil samples ( $V \%$ elevated to 70$)$, and the surfacelayer (0-0.2 $\mathrm{m}$ ) supplemented with $\mathrm{Cd}$-contaminated biosolid (sewage sludge, $\mathrm{pH}$ 6). The biosolid treatments were contaminated as follows (in mg kg-1): 0 (control) 2,500 of Cd, 5,000 of Cd, 2,500 of Cd $+2,500$ of $\mathrm{Pb}$, and 5,000 of $\mathrm{Cd}+5,000$ of $\mathrm{Pb}$. The soil col umns were cultivated with maize for a period of 80 days. The total $\mathrm{Cd}$ concentrations in the soil samples and maize shoots were determined using nitro-perchl oric extraction solution. Therewas no percolation of $\mathrm{Cd}$ into the soil column, so the high amounts of cadmi um remained in the surfacelayer. The concentration of $12 \mathrm{mg} \mathrm{kg}^{-1}$ of Cd in themaizeshoots was not enough to causevisibletoxicity symptoms in the plants. Pb, applied together with $\mathrm{Cd}$, did not affect the soil-plant system.
\end{abstract}

Index terms: sewagesludge, leaching, toxicity, $\mathrm{Pb}$.

\section{INTRODUÇÃO}

A preocupação com o destino final da grande quantidade de resíduos urbano-industriais, como o lodo de esgoto, produzidos pela atividade humana é crescente na sociedade moderna. Esselodo de esgoto, quando processado pelas Estações deTratamento de Esgoto (ETE ), com vistas em permitir o seu manuseio de forma segura na agricultura, é chamado de biossólido.

A aplicação do biossólido na agricultura está se tornando prática comum, já que as estações de tratamento de lodo de esgoto não dispõem de outro destino (Hervas, 1996), uma vez que esse material encerra em sua composição consideráveis teores de matéria orgânica e nutrientes (Oliveira et al., 1995). Apesar dos efeitos benéficos da incorporação do biossólido ao solo, existe o problema dos metais pesados que, ao acumularem no solo e nas plantas, causam sérios riscos à saúde humana, propagandose nos diversos níveis da cadeia alimentar (Chang et al., 1997).

Dentre os metais pesados presentes no biossólido, o cádmi o é uma importante fonte de contaminação (Robards, 1991), em virtude de sua longa persistência no solo, o que facilita sua bioacumulação (Larini, 1993).

Um sol o considerado contaminado para cádmio, segundo os padrões de qualidade do solo, pode variar de 1-3 $\mathrm{mg} \mathrm{kg}^{-1}$ (Hall, 1998), segundo Diretriz da Comunidade Européia, e até $20 \mathrm{mg} \mathrm{kg}^{-1}$, segundo United States Environmental Protections Agency (USEPA) dos EUA. Para predizer esses teores no sol o, têm si do utilizados extratores ácidos, agressivos, como o ácido perclórico, que estimam o Cd próximo ao teor total (Horwitz, 1980) ou ácido clorídrico (Takijima et al., 1973; Mattiazzo-Prezotto, 1994). Por essa razão, recomendam-se estudos de monitoramento, dos teores do el emento no solo, para evitar atingir teores tóxicos, os quais podem afetar a cadeia alimentar.

É importanteressaltar que o poder contaminante de um metal pesado pode ser caracterizado pelo potencial de movimento no solo. Alguns autores indicam existir certa mobilidade do $\mathrm{Cd}$ no solo, especial mente em condições de sol os áci dos (Amaral Sobrinho et al., 1998), dada a menor ocorrência dos fenômenos de adsorção e co-precipitação, uma vez que o aumento do $\mathrm{pH}$ incrementa a taxa de adsorção deste el emento no sol o (Dias et al ., 2001), enquanto outros colocam-no como praticamente imóvel no perfil do solo (Chang et al., 1984; Li et al., 1994).

Diante desse contexto, o presente experimento foi desenvolvido, objetivandoavaliar a biodisponibilidade e a mobilidade Cd no sistema solo-planta, utilizando biossól ido contami nado com $\mathrm{Cd}$ e Pb, em colunas com solo cultivado com milho.

\section{MATE RIAL E MÉTODOS}

Foram col etadas amostras do $L$ atossol oVermel ho distrófico típico do campus da Universidade Estadual de Maringá, em camadas de 0,20 m aténa profundidade de $0,80 \mathrm{~m}$. Em seguida, as amostras foram peneiradas e secas ao ar. A análise química do sol o foi efetuada de acordo com método descrito por Pavan et al. (1992), e a análise física, conforme método descrito por EMBRAPA (1997). O solo 
apresentou as seguintes características: pH emágua $=5,3 ; \mathrm{K}=0,4 ; \mathrm{Ca}=0,8 ; \mathrm{Mg}=0,4 ; \mathrm{H}+\mathrm{Al}=$ $0,8 \mathrm{mmol}_{\mathrm{c}} \mathrm{dm}^{-3} ; \mathrm{Fe}=114,7 ; \mathrm{Cu}=3,0 ; \mathrm{Mn}=$ $75,7 \mathrm{mg} \mathrm{dm}^{-3}$; argila $=320$; silte $=20$ e areia $=$ $660 \mathrm{~g} \mathrm{~kg}^{-1}$.

Determinou-se a necessidade de calagem do solo pelo método SMP (Pavan et al., 1992), el evando o valor de pH para aproximadamente 6,0, utilizandose de uma mistura $\mathrm{CaCO}_{3}: \mathrm{MgCO}_{3}$, na relação $3: 1$ (em partes). O corretivo de acidez foi misturado ao solo, permanecendo incubado durante 15 dias.

O biossólido ( $70 \%$ de umidade) foi obtido na estação de tratamento de esgoto da SANEPAR (Companhia de Saneamento de Paraná), em Maringá. Logo após a coleta, foi feita a análise química do produto in natura, digerida com solução nitro-perclórica, e os teores de K, Ca, Mg, S, Cu, Zn, $\mathrm{Fe}, \mathrm{Mn}, \mathrm{Pb}$ e $\mathrm{Cd}$ foram determinados por meio de métodos descritos por Hor witz (1980). Os el ementos $\mathrm{N}, \mathrm{P}$ e $\mathrm{C}$ foram analisados conforme Pavan et al. (1992). As características químicas do biossólido foram as seguintes, em $\%, N=2,9 ; P=0,8 ; K=0,1$; $\mathrm{Ca}=3,0 ; \mathrm{Mg}=1,0 ; \mathrm{S}=0,3 ; \mathrm{C}=24,3 \mathrm{e}, \mathrm{em} \mathrm{mg} \mathrm{kg}^{-1}$, $\mathrm{Cu}=146 ; \mathrm{Zn}=132 ; \mathrm{Fe}=612 ; \mathrm{Mn}=262 ; \mathrm{Pb}=122 \mathrm{e}$ $\mathrm{Cd}=3,5$.

Objetivando elevar o valor de pH para 6,0, foi aplicada nobiossólido uma mistura de $\mathrm{CaCO}_{3}: \mathrm{MgCO}_{3}$, na relação 3:1 (partes), permanecendo incubado por 28 dias, mantendo umidade em $80 \%$ da capacidade de campo. Salienta-se que um motivo que leva à aplicação de material corretivo em biossólido seria a medida de higienização contra organismos patogênicos. Logo após a incubação de quatro semanas, adicionaram-se ao biossólido doses de $\mathrm{Cd}$ e $\mathrm{Pb}$, usando como fonte os sais $\mathrm{CdCl}_{2}$ e $\mathrm{PbCl}_{2}$.

O delineamento experimental foi inteiramente ao acaso, com cinco tratamentos e três repetições. Os tratamentos foram constituídos pelas respectivas doses de Cd e Pb, em mg kg-1: (a) 0 e 0; (b) 2.500 e 0; (c) 5.000 e 0; (d) 2.500 e 2.500; (e) 5.000 e 5.000, respectivamente. A quantidade de biossólido utilizada correspondeu a $6 \mathrm{Mg} \mathrm{ha}^{-1}$ (base seca), incorporada ao sol o na camada de 0-0,2 m da coluna.

As colunas de PVC foram montadas, conforme Silva et al. (1999), com saídas laterais a cada 0,10 m, a partir dos primeiros $0,20 \mathrm{~m}$ até $0,60 \mathrm{~m}$ de profundidade, onde foram colocados tubos-sonda preenchidos com sol o correspondente ao da camada da col una, para posterior análise. Estes tubos-sonda foram perfurados na parte interna com a finalidade de permitir a passagem da solução do solo, juntamente com o contami nante, permitindo, assim, determinar sua percolação (Figura 1).

Após a instalação do experimento, foram semeadas cinco sementes de milho (híbrido C 444), deixando-se após o desbaste, aos sete dias da emergência, três plantas em cada coluna.

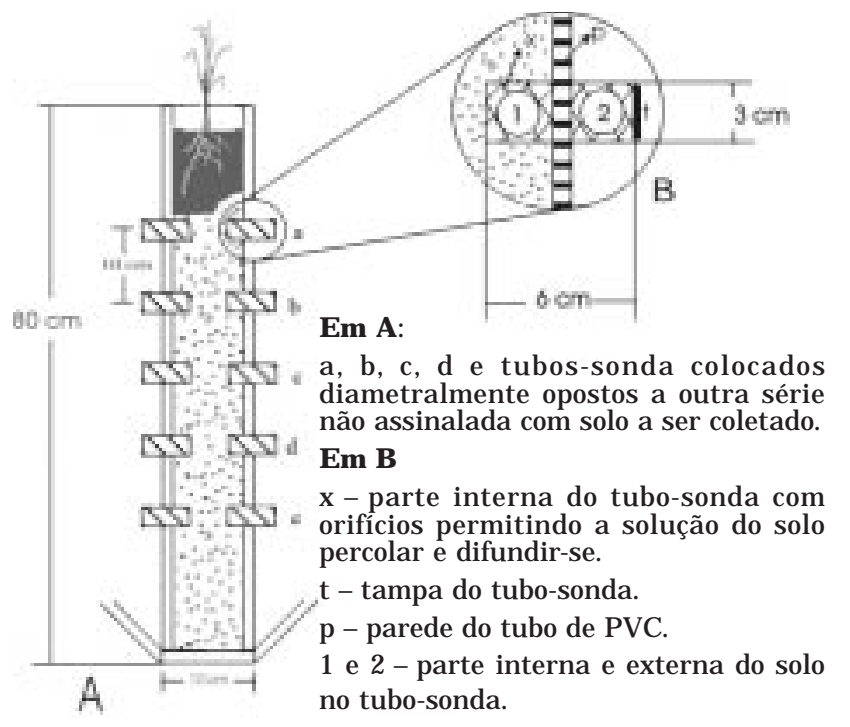

Figura 1. Representação de um corte vertical frontal do tubo de PVC ( $f=10 \mathrm{~cm}$ e altura $=$ $80 \mathrm{~cm}$ ), que continha o solo e os tubos-sonda (Parte A). E, ampliação de um corte do tubosonda (Parte B).

Para permitir a lixiviação do $\mathrm{Cd}$, durante esse período (80 dias), uma vez por semana, as regas foram feitas com uma quantidade deágua duas vezes superior à maior precipitação dos últimos 21 anos (152 mm do dia 05/06/1997), segundo dados do Departamento de Meteorologia da UEM, correspondendo a 1,52 $\mathrm{L}$ de água por coluna.

Depois de oitenta dias de cultivo, realizou-se a col heita da parteaérea das plantas, secandoo material em estufa, de circulação de ar a $80^{\circ} \mathrm{C}$, por $48 \mathrm{~h}$.

A coleta das amostras de solo (camada de 00,20 m e amostra dos tubos-sonda) foi realizada 15 dias após a colheita. Ressalta-se que, imediatamente após a colheita, suspendeu-se a irrigação e aguardou-se esse período (15 dias) para redução e homogenização da umidade ao longo da coluna, para posterior col eta das amostras de solo. O material de cada tubo-sonda foi dividido em partes, externa e interna, ao tubo de PVC. As amostras foram secas ao ar, trituradas em gral de porcelana, peneiradas eacondicionadas em recipientes fechados e submetidas às análises químicas.

As amostras de solo, da água percolada e de plantas foram digeridas, por via úmida, utilizando a solução nitro-perclórica (Horwitz, 1980), determinando-se o cádmio. Salienta-se que para extração do cádmio total exige-se digestão com ácido fluorídrico juntamente com áci dos fortes; entretanto, o ácido fluorídrico geralmente não é utilizado na rotina dos laboratório pelo difícil manuseio. Assim sendo, é comum utilizar ácidos alternativos, como perclórico, para estimar teores do Cd próximoaototal. 
Os dados foram submetidos a uma análise de variância, utilizando o teste de Tukey, para comparação de médias e à análise de regressão polinomial, para avaliar os efeitos das doses. O software utilizado na análise estatística foi o SANEST (Udo \& Santana, 1996).

\section{RESULTADOS E DISCUSSÃO}

Para a produção de matéria seca, verificou-se que não houve diferença significativa $\left(R^{2}=0,40^{\text {ns }}\right)$ entre os tratamentos e a testemunha, mostrando que a aplicação do metal no sol o não afetou o crescimento das plantas, nem o $\mathrm{Pb}$ interferiu na resposta do $\mathrm{Cd}$ (Figura 2a).

A aplicação de altas dose de $\mathrm{Cd}$ no solo não foi suficiente para atingir toxidez, visto que o $\mathrm{Cd}$ absorvido não correlacionou $\left(R^{2}=0,30^{\text {ns }}\right)$ com a produção de matéria seca (Figura 2b).

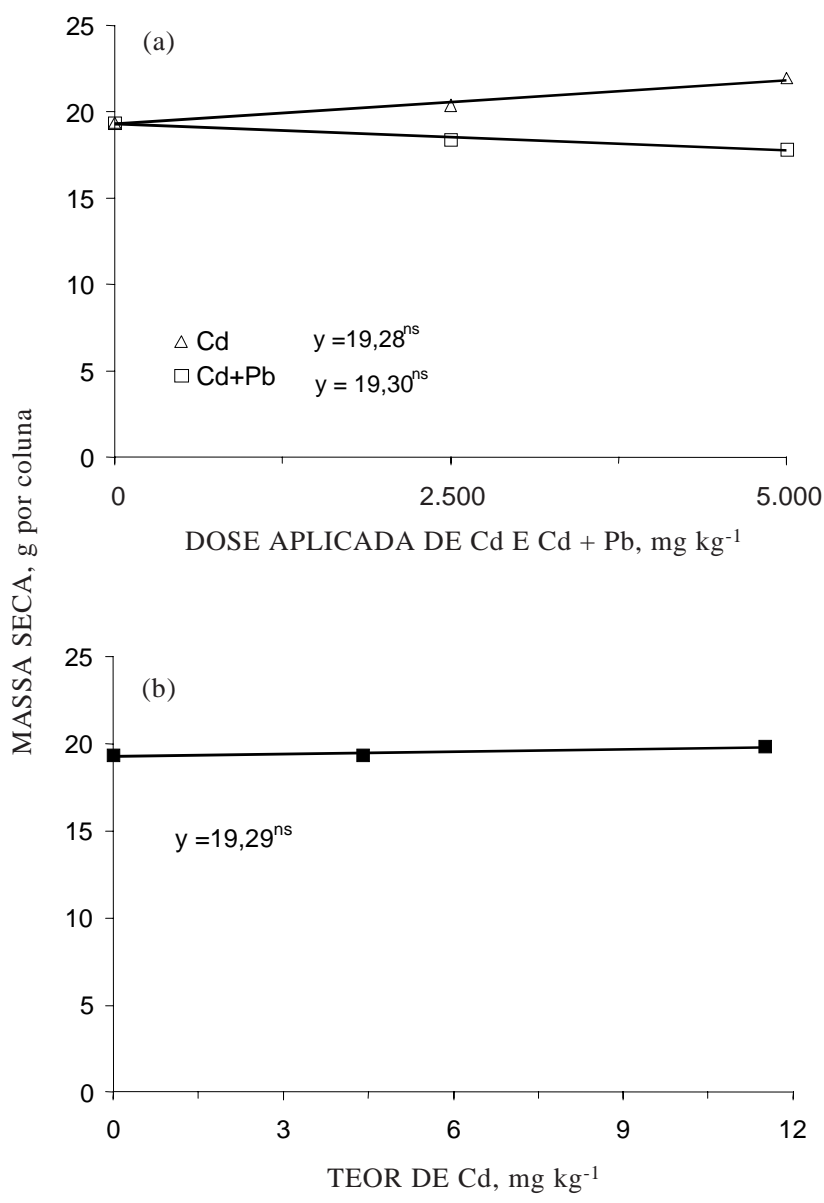

Figura 2. Efeito da aplicação de biossólido contaminado com $\mathbf{C d}$ na produção de massa seca (a) e a relação do teor de $\mathrm{C}$ d e a produção de massa seca (b) do milho.
Pela literatura, é comum inferir que esta tolerância da planta ao Cd pode ser atribuída a mecanismos de defesa da planta, visto que estudos têm mostrado que plantas submetidas ao $\mathrm{Cd}$ aumentam a produção de fitoquelatinas, as quais apresentam propriedades quelantes, que agem na planta (Barceló \& Poschenrieder, 1992).

Embora a aplicação de $\mathrm{Cd}$ não tenha causado redução na massa seca da parte aérea do milho, observou-se um acúmulo linear na concentração de Cd total na camada superficial do solo (0-0,20 m de profundidade), tanto pela aplicação do $\mathrm{Cd}$ isolado como associado ao Pb (Figura 3). Observou-sequea aplicação da maior dose de $\mathrm{Cd}\left(5.000 \mathrm{mg} \mathrm{kg}^{-1}\right)$ causou uma concentração de $41,8 \mathrm{mg} \mathrm{kg}^{-1}$, sendo o solo considerado contaminado segundo os padrões de qual idade, visto que a U nited States Environmental Protections Agency (USEPA), dos EUA, estabel eceo teor tóxico de $20 \mathrm{mg} \mathrm{kg}^{-1}$; a Diretriz da Comunidade Européia, de $1-3 \mathrm{mg} \mathrm{kg}^{-1}$ (Hall, 1998), e Pepin \& Coleman (1984), de 3-8 $\mathrm{mg} \mathrm{kg}^{-1}$. Nota-se grande variação entre os autores para o teor de Cd tóxico no sol o, o que dificulta comparação com a literatura, visto que existem diversos fatores que podem interferir, tais como: a mineral ogia ea reação do sol o, os métodos químicos empregados e as suas derivações. De qualquer forma, observa-se que o biossól i do contaminado utilizado transformou-se em fonte de contaminação de $\mathrm{Cd}$ no solo, conforme também verificado por outros autores (KabataPendias \& Pendias, 1992).

Quanto às outras profundidades $(0,20-0,60 \mathrm{~m})$ (Quadro 1), não houve diferença significativa de concentração de $\mathrm{Cd}$ na parteinterna dos tubos-sonda nas várias profundidades, quando comparadas com a testemunha, mostrando que o metal adicionado na forma de sais não lixiviou no solo, concordando com Chang et al . (1984) eLi et al . (1994) ediscordando deAmaral Sobrinho et al . (1998) que al egaram ser a

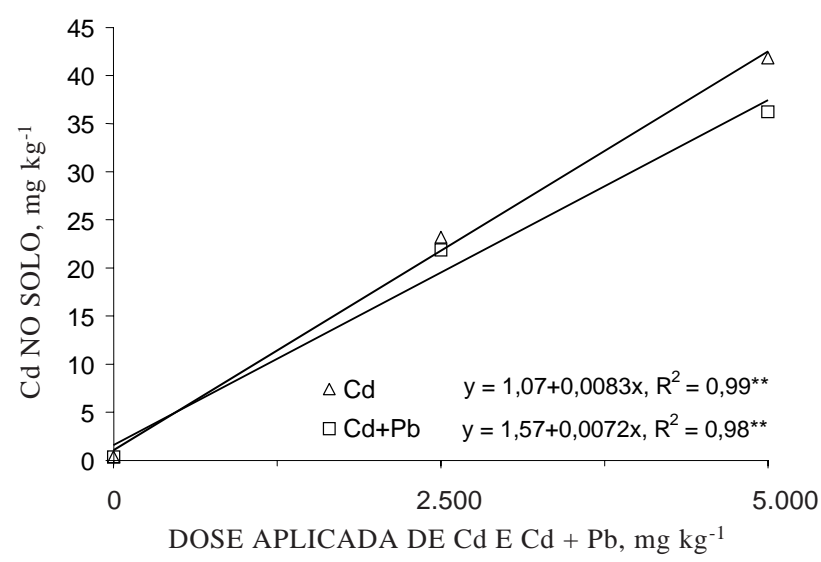

Figura 3. Efeito da aplicação de biossólido contaminado com $\mathrm{Cd}$ na sua concentração no solo, camada da coluna de $0-0,20 \mathrm{~m}$ de profundidade. 
maior mobilidade do Cd no sol o justificada por estar grande parte do Cd total do sol o na forma trocável. Por outrolado, a falta de lixiviação do Cd na coluna pode ser devida à co-precipitação com óxidos de Fee Mn (Bell et al., 1991), constituinte comum, em solos tropicais, que predominam argila tipo 1:1, a exemplo do utilizado neste trabalho. Soma-se a isso o efeito $\mathrm{pH}$, em decorrência de doses de carbonato de cálcio e de magnésio que o sol o recebeu para neutralização da acidez, uma vez que Dias et al. (2001) observaram, em sol o semel hante ao estudado, que a el evação do valor pH aumentou a adsorção de $\mathrm{Cd}$ no solo.

Quanto à absorção de Cd pelo milho, observou-se que não houve diferença significativa entre os tratamentos $\mathrm{Cd} 2.500$ e Cd $2.500+\mathrm{Pb} 2.500$, nem entreos tratamentos Cd 5.000 eCd $5.000+\mathrm{Pb} 5.000$, mostrando que o $\mathrm{Pb}$ não interferiu na concentração do Cd na parteaérea do mil ho (Quadro 2), da mesma forma que ocorreu com as concentrações de $\mathrm{Cd}$ do solo (Figura 4).

Como não ocorreu diferença entre os tratamentos $(\mathrm{Cd}$ e $\mathrm{Cd}+\mathrm{Pb})$, observou-se um incremento linear na concentração de $C d$ na parte aérea do mil ho com a aplicação do biossólido contaminado (Figura 4). Portanto, estes resultados discordam dos de Beckett (1991), que coloca que os metais pesados não são absorvidos pel as plantas proporcionalmente aos seus teores no solo, usando o extrator $\mathrm{HCl}$, para avaliar a disponibilidade de $\mathrm{Cd}$. Tais resultados podem ser explicados pelo tipo de extrator utilizado, que possibilita estimar, com eficiência, o el emento disponível para as plantas, considerando a alta correlação obtida neste trabal ho.
Estes resultados indicam que o extrator nitroperclórico pode ser utilizado para predizer o $\mathrm{Cd}$ absorvido pela planta. Entretanto, é importante destacar que as doses de Cd utilizadas foram altas, o que podeter favorecido a alta correlação obtida, daí a necessidade de mais estudos para confirmar esse resultado. Outros autores têm obtido resultados favoráveis, utilizando extrator ácido $\left(\mathrm{HCl} \mathrm{0,1} \mathrm{mol} \mathrm{L}^{-1}\right)$, para predizer os teores de $\mathrm{Cd}$ do solo (Takijima et al., 1973; Mattiazzo-Prezotto, 1994).

Por outro Iado, Anjos \& Mattiazzo (2001), trabalhando com os extratores água-régia, $\mathrm{HCl}$ 0,1 mol L-1; Mehlich-3 e DTPA-TEA pH 7,3, para quantificar o Cd em sol os que receberam biossólido, observaram que nenhum extrator foi eficiente na previsão da disponibilidade deste elemento. Entretanto, segundo os autores, a falta de correl ação entre a extração de $\mathrm{Cd}$ pel os extratores e a absorção de $\mathrm{Cd}$ pela planta pode ser atribuída à baixa dose desse el emento aplicado ao solo, tendo o teor total médi o de Cd atingi do apenas $4,1 \mathrm{mg} \mathrm{dm}^{-3} \mathrm{e}$, com isso, o el emento contido na planta esteve abaixo do limite de determinação do método analítico empregado.

Pelos resultados, a maior dose de $\mathrm{Cd}$ resultou em al ta concentração no solo (até $41,8 \mathrm{mg} \mathrm{kg}^{-1}$ ) (Figura 3) que, por sua vez, atingiu a concentração na parte aérea do milho de $12 \mathrm{mg} \mathrm{kg}^{-1}$ (Figura 4). Macnicol \& Beckett (1985) observaram que, no milho, a concentração que diminuiu o crescimento da planta ocorreu com $25 \mathrm{mg} \mathrm{kg}^{-1}$; portanto, neste experimento, a planta absorveu uma quantidade de Cd abaixo da concentração de visualização dos sintomas de toxidez. Assim, percebe-se que o milho é capaz de

Quadro 1. Concentração de Cd no solo, em diferentes estratos de profundidade e posições da coluna ou tubo-sonda, após o cultivo de milho durante 80 dias

\begin{tabular}{|c|c|c|c|c|c|c|}
\hline \multirow{2}{*}{\multicolumn{2}{|c|}{ Profundidade }} & \multicolumn{5}{|c|}{ Tratamento } \\
\hline & & Testemunha & Cd 2.500 & Cd 5.000 & Cd $2.500+P b 2.500$ & Cd $5.000+$ Pb 5.000 \\
\hline \multicolumn{2}{|c|}{$\mathrm{cm}$} & & 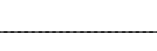 & $\mathrm{mg} \mathrm{kg}^{-1}$ & 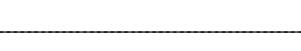 & - \\
\hline \multicolumn{2}{|c|}{ Superfície } & 0,38 a & $23,19 a$ & $41,84 \mathrm{a}$ & $21,89 a$ & $36,26 \mathrm{a}$ \\
\hline $\begin{array}{l}20 \\
20\end{array}$ & $\begin{array}{l}\mathrm{I} \\
\mathrm{E}\end{array}$ & $\begin{array}{l}1,07 \mathrm{~b} \\
1,08 \mathrm{~b}\end{array}$ & $\begin{array}{l}1,51 \mathrm{~b} \\
1,47 \mathrm{~b}\end{array}$ & $\begin{array}{l}1,73 \mathrm{~b} \\
1,22 \mathrm{~b}\end{array}$ & $\begin{array}{l}1,19 \mathrm{~b} \\
1,06 \mathrm{~b}\end{array}$ & $\begin{array}{l}1,95 \mathrm{~b} \\
0,91 \mathrm{~b}\end{array}$ \\
\hline $\begin{array}{l}30 \\
30\end{array}$ & I & $\begin{array}{l}1,11 \mathrm{~b} \\
1,13 \mathrm{~b}\end{array}$ & $\begin{array}{l}1,65 \mathrm{~b} \\
1,67 \mathrm{~b}\end{array}$ & $\begin{array}{l}1,48 \mathrm{~b} \\
1,40 \mathrm{~b}\end{array}$ & $\begin{array}{l}1,21 \mathrm{~b} \\
1,17 \mathrm{~b}\end{array}$ & $\begin{array}{l}1,40 \mathrm{~b} \\
1,02 \mathrm{~b}\end{array}$ \\
\hline $\begin{array}{l}40 \\
40\end{array}$ & I & $\begin{array}{l}1,23 \mathrm{~b} \\
1,17 \mathrm{~b}\end{array}$ & $\begin{array}{l}1,79 \mathrm{~b} \\
1,84 \mathrm{~b}\end{array}$ & $\begin{array}{l}1,42 \mathrm{~b} \\
1,48 \mathrm{~b}\end{array}$ & $\begin{array}{l}1,17 \mathrm{~b} \\
1,18 \mathrm{~b}\end{array}$ & $\begin{array}{l}1,10 \mathrm{~b} \\
0,99 \mathrm{~b}\end{array}$ \\
\hline $\begin{array}{l}50 \\
50\end{array}$ & $\begin{array}{l}\mathrm{I} \\
\mathrm{E}\end{array}$ & $\begin{array}{l}1,21 \mathrm{~b} \\
1,18 \mathrm{~b}\end{array}$ & $\begin{array}{l}1,85 \mathrm{~b} \\
1,90 \mathrm{~b}\end{array}$ & $\begin{array}{l}1,48 \mathrm{~b} \\
1,49 \mathrm{~b}\end{array}$ & $\begin{array}{l}1,12 \mathrm{~b} \\
1,14 \mathrm{~b}\end{array}$ & $\begin{array}{l}0,91 \mathrm{~b} \\
1,00 \mathrm{~b}\end{array}$ \\
\hline $\begin{array}{l}60 \\
60\end{array}$ & I & $\begin{array}{l}1,25 \mathrm{~b} \\
1,26 \mathrm{~b}\end{array}$ & $\begin{array}{l}1,89 \mathrm{~b} \\
1,90 \mathrm{~b}\end{array}$ & $\begin{array}{l}1,54 \mathrm{~b} \\
1,55 \mathrm{~b}\end{array}$ & $\begin{array}{l}1,18 \mathrm{~b} \\
1,20 \mathrm{~b}\end{array}$ & $\begin{array}{l}1,05 \mathrm{~b} \\
1,05 \mathrm{~b}\end{array}$ \\
\hline D.M.S. & & 0,18 & 2,98 & 1,69 & 5,45 & 2,88 \\
\hline C.V. (\%) & & 5,6 & 27,6 & 11,3 & 61,3 & 22,8 \\
\hline
\end{tabular}

I - parte interna do tubo-sonda; E - parte externa do tubo-sonda. Médias seguidas por letras distintas, na vertical, diferem entre si pelo teste de Tukey $(p<0,05)$. 
Quadro 2. Concentração de Cd na parte aérea das plantas de milho cultivadas em coluna com solo

\begin{tabular}{lc}
\hline \multirow{2}{*}{ Tratamento } & Cd \\
\cline { 2 - 2 } & Média \pm desvio-padrão \\
\hline & $\mathrm{mg} \mathrm{kg}^{-1}$ \\
Testemunha & $\mathrm{n} . \mathrm{d}$. \\
Cd 2.500 & $4,33 \mathrm{~b} \pm 0,49$ \\
Cd 5.000 & $12,16 \mathrm{c} \pm 2,00$ \\
Cd $2.500+\mathrm{Pb} 2.500$ & $4,46 \mathrm{~b} \pm 0,48$ \\
Cd $5.000+\mathrm{Pb} 5.000$ & $10,84 \mathrm{c} \pm 2,90$ \\
D.M.S & 4,21 \\
C.V. (\%) & 24,7 \\
\hline
\end{tabular}

Médias seguidas por letras distintas, na vertical, diferem entre si pelo teste de Tukey $(p<0,05)$. nd: Não-determinado (teores abaixo do limite de detecção do método analítico utilizado).

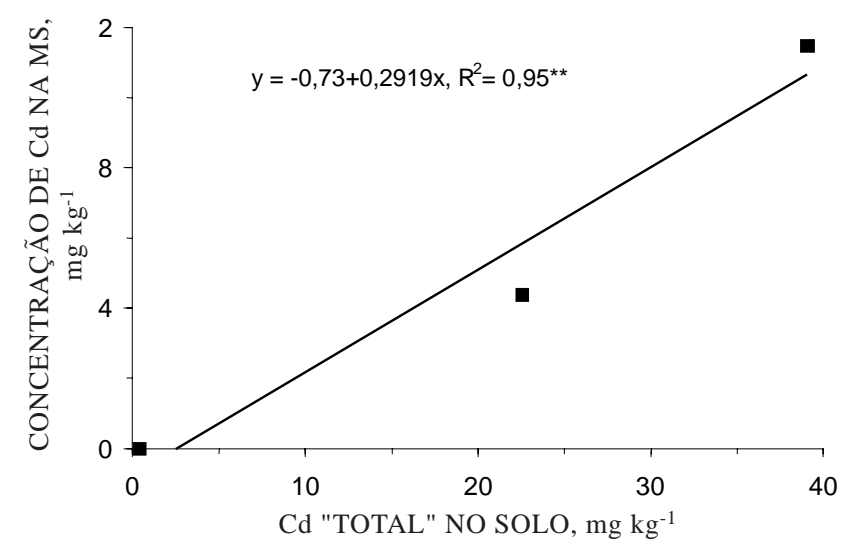

Figura 4. Relação entre o teor de Cd extraído com ácido nitro-perclórico no solo e com a sua concentração na parte aérea do milho (média de doses de $\mathrm{Cd}$ e de $\mathrm{Cd}+\mathrm{Pb}$ ).

absorver uma quantidade considerável de $\mathrm{Cd}$, mesmo sem apresentar sintomas visuais de fitotoxidez, mesmo em solos considerados contaminados $\left(41,8 \mathrm{mg} \mathrm{kg}^{-1}\right)$. Anjos \& Mattiazzo (2000) observaram que o solo que recebeu biossólido com contaminação por $\mathrm{Cd}$ (total) de $4 \mathrm{mg} \mathrm{kg}^{-1}$, extraído com água régia, não apresentou teores detectáveis de $\mathrm{Cd}$ em plantas de milho. Amaral et al . (1994), cultivandoalfaceem sol o contaminado com até 34,6 mg kg-1 deCd (extrator nitro-perclórico), não observaram sintomas visíveis de toxidez.

Estes resultados também permitem inferir queo prévio tratamento do solo e também do biossólido, com carbonatos, pode aumentar a viabilidade do uso do biossólido na agricultura, considerandoa ausência de mobilidade no perfil do sol o e a falta de sintomas visuais de toxidez em plantas de milho.

Entretanto, é prudente consi derar que as plantas, mesmo com certo teor de contaminação, a exemplo deste trabal ho (Cd na parte aérea igual a $12 \mathrm{mg} \mathrm{dm}^{-3}$ ), podem não apresentar sintomas visuais de toxidez, indicando que o consumo alimentício de plantas, especialmente "in natura", sem devidas precauções, pode ser perigoso, pois estas podem estar contaminadas com metais pesados e isto não ser visualmente percebido.

\section{CONCLUSÕES}

1. A alta concentração do Cd total no Latossolo Vermel ho restringiu-se apenas à camada de sua incorporação, de forma que não houve movimento do el emento na coluna do solo.

2. A concentração de $12 \mathrm{mg} \mathrm{kg}^{-1}$ de Cd na planta não foi suficiente para provocar sintomas de fitotoxidez de $\mathrm{Cd}$ em milho.

3. $\mathrm{O} \mathrm{Pb}$ adicionado juntamente com o $\mathrm{Cd}$ não apresentou interferência no sistema solo-milho.

\section{AGRADECIMENTOS}

AoCNPq, pela bolsa concedida à primeira autora, e ao SANEPAR (Companhia de Saneamento de Paraná), pelo constante apoio.

\section{LITE RATURA CITADA}

AMARAL SOBRINHO, N.M.B.;VELLOSO,A.C.X.\& OLIVEIRA, C. Mobilidade de metais pesados em solo tratado com resíduo siderúrgicoácido. R. Bras. Ci. Solo, 22:345-353, 1998.

AMARAL, A.S.; DEFELIPO, B.V.; COSTA,L.M. \& FONTES, M.P.F. Liberação de Zn, Fe, Mn, $\mathrm{Cd}$ ePb de quatro corretivos de acidez do sol o e absorção por alface, em dois solos. Pesq. Agropec. Bras., 29:1351-1358, 1994.

ANJ OS, A.R.M. \& MATTIAZZO, M.E. Extratores para Cd, Cu, $\mathrm{Cr}, \mathrm{Mn}, \mathrm{Ni}, \mathrm{Pb}$ e Zn em Latossolos tratados com biossólido e cultivados com milho. Sci. Agric., 58:337-344, 2001.

ANJ OS, A.R.M . \& MATTIAZZO, M.E. Metais pesados em plantas de milho cultivadas em Latossol os repetidamente tratados com biossólido. Sci. Agric., 57:769-776, 2000.

BARCELÓ, J . \& POSCHENRIEDER, C. Respuestas de las plantas a la contaminacion por metales pesados. Suelo Planta, 2:345-361,1992.

BECKETT, P.H.T. Critical tissue concentrations as indicators of toxicity. Suelos Ecuatoriales, 21:39-44, 1991.

BELL, P.F.; JAMES, B.R. \& CHANEY, R.L. Heavy metal extractability in long-term sewage sludge and metal saltamended soils. J. Environ. Qual., 20:481-486, 1991. 
CHANG, A.C.; HYUN, H. \& PAGE, A.L. Cadmium uptake for swiss chard growm on composted sewage sludge treated field plots: plateau or time bomb. J. Environ. Qual., 26:1119, 1997.

CHANG, A.C.; WARNEKE, J.E.; PAGE, A.L. \& LUND, L.J . Accumulation of heavy metals in sewage sludge - treated soils. J. Environ. Qual., 13:87-91,1984.

DIAS, N.M.P.; ALLEONI, L.R.F.; CASAGRANDE, J.C. \& CAMARGO, O.A. Adsorção de cádmio em dois Latossolos ácricos e um Nitossolo. R. Bras. Ci. Solo, 25:297-304, 2001

EMPRESA BRASILEIRA DE PESQUISA AGROPECUÁRIA EMBRAPA. Manual de métodos de análises de solo. Rio de J aneiro, Centro Nacional de Pesquisas de Solos, 1997. 212p.

$H A L L, J$. Standardising and the management of biosolids the international experience. In: SEMINÁRIO SOBRE GERENCIAMENTO DE BIOSSÓLIDOS DO MERCOSUL, 1., Curitiba, 1998. Anais. Curitiba, SANE PAR;ABEAS, 1998. p.113-122.

HERVAS, D.A. Dinâmica de metais pesados no sistema soloplanta, influenciada pela calagem, pel otempo de incubação e pelas doses, quando incorporados no solo via biossólido. Viçosa. Universidade Federal de Viçosa, 1996. 80p. (Tese de Mestrado)

HORWITZ, W. Official methods of analysis of the association of official analytical chemists - AOAC. 13.ed. Washington, TheAssociation of Official Analytical Chemists, 1980. p.30.

KABATA-PENDIAS, A. \& PENDIAS, H. Trace elements in soils and plants. 3.ed. Boca Raton, CRC Press, 1992. p.74-143.

LARINI, L. Toxicologia. 2.ed. São Paulo, Manole, 1993. p.128-130.

LI, Y.M.; CHANEY, R.L. \& SCHNEITER, A.A. Effect of soil chloride level on cadmium concentration in sunflower kernels. Plant Soil, 167:275-280, 1994.
MACNICOL, R.D. \& BECKETT, P.H.T. Critical tissue concentrations of potentially toxic elements. Plant Soil, 85:107-129, 1985.

MATTIAZZO-PREZOTTO, M.E. Comportamento de Cu, Cd, Cr, $\mathrm{Ni}$ e $\mathrm{Zn}$ adicionados a solos de clima tropical em diferentes valores de pH. Piracicaba, Escola Superior de Agricultura “Luiz de Queiroz", 1994.197p. (Tese Livre-Docência)

OLIVEIRA, F.C.; MARQUES, M.O.; BELLINGIERI, P.A. \& PERECIN, D. Biossólido como fonte de macronutrientes para a cultura do sorgo granífero. Sci. Agric., 52:360-367, 1995.

PAVAN, M.A.; BLOCH, M.F.; ZEMPULSKI, H.C.; MIYAZAWA, M. \& ZOCOLER, D.C. Manual de análise química do soloe controle de qualidade. Londrina, IAPAR, 1992. p.7-18. (Circular, 74)

PEPIN, R.G. \& COLEMAN, P. Paper mill sludge and ash as soil conditioner. J . Waste Recyc., 25:52-54, 1984.

ROBARDS, K. Cadmium: toxicology and analysis. Analyst, 116:549-568, 1991.

SILVA, M.S.; LENZI, E. \& LUCHESE, E.B. Comportamento do chumbo em solo argiloso tratado com lodo de esgoto contaminado e sua absorção pelas plantas. Acta Scient., 21:757-762, 1999.

TAKIJIMA, Y.; KATSUMI \& KOIZUMI, S. Cadmium contamination of soils and rice plants caused by zinc mining. V. Removal of soil cadmium by na $\mathrm{HCl}$-leaching method for the control of high Cd rice. Soil Sci. Plant Nutr., 19:245254, 1973.

UDO, M.T. \& SANTANA, R.G. Análise de variância - I Parte, Maringá, Universidade Estadual de Maringá, 1996. p.114. (Apontamentos, 50) 
M.A. J ULIATTI et al.

R. Bras. Ci. Solo, 26:1075-1081, 2002 